\title{
Ultrastructure of Hyrtl's Anastomosis of Pregnancy Induced Hypertensive Umbilical Arteries
}

\author{
Karma Lakhi Bhutia ${ }^{1}$, Khrieketouzo Atou Chielie ${ }^{2}$, Poonam Shilal ${ }^{3}$, Jerina Tewari ${ }^{4}$, Benoy Upreti ${ }^{5}$ \\ 1, 2, 3, 4,5 Department of Anatomy, Sikkim Manipal Institute of Medical Sciences, Gangtok, Sikkim, India.
}

\section{ABSTRACT}

\section{BACKGROUND}

The human umbilical arteries form an important component involved in the exchange of materials between the foetus and the mother. Hypertensive disorders in pregnancy are responsible for a significant amount of maternal and perinatal morbidity and mortality. It complicates about $6-20 \%$ of all pregnancies. Although $\mathrm{PIH}$ (Pregnancy-induced hypertension) is one of the major causes of maternal death, especially in developing countries; its perinatal outcomes are also not so favourable. We wanted to study the ultrastructure of Hyrtl's anastomosis between the normotensive and hypertensive placentas.

\section{METHODS}

A cross-sectional study was carried out to assess the variable anatomy in Hyrtl's anastomosis and determine the alterations of the Hyrtl's anastomosis in the case of pregnancy-induced hypertension from the year 2017-2018 at Sikkim Manipal Institute of Medical Sciences. For TEM (transmission electron microscopy) the portion of the Hyrtl's anastomosis was carefully dissected out and processed. The study included women with pregnancy-induced hypertension if their arterial blood pressure with systolic as $\geq 140 \mathrm{~mm} \mathrm{Hg}$ and diastolic $\geq 90 \mathrm{~mm} \mathrm{Hg}$ measured on two or more occasions at least after the $20^{\text {th }}$ week of gestation with or without oedema. Due to an inadequate number of cases essential hypertensive cases were excluded.

\section{RESULTS}

From the study conducted, transmission electron microscopy revealed a disrupted muscular layer in pregnancy-induced hypertension when compared to normal Hyrtl's anastomosis. Thickening of the muscular layer was observed in the pregnancy-induced Hyrtl's anastomosis. Statistical Analysis - Independent t-test was considered in the analysis for continuous among the ultrastructure of the Hyrtl's anastomosis between the normotensive and hypertensive groups. $\mathrm{P} \leq 0.05$ was considered significant. SPSS 20.0 was used for data analysis.

\section{CONCLUSIONS}

The effect of hypertension brought about structural changes in the blood vessel which might probably have an effect on the fetoplacental circulation and therefore adversely affecting the foetal outcome.

\section{KEY WORDS}

Hyrtl's Anastomosis, Pregnancy- Induced Hypertension
Corresponding Author: Dr. Khrieketouzo Atou Chielie, Assistant Professor, Department of Anatomy, Sikkim Manipal Institute of Medical Sciences, $5^{\text {th }}$ Mile Tadong, Gangtok-737102, Sikkim, India. E-mail:kcchielie@yahoo.co.in

\section{DOI: $10.14260 / \mathrm{jemds} / 2021 / 702$}

How to Cite This Article: Bhutia KL, Chielie KA, Shilal P, et al. Ultrastructure of Hyrtl's anastomosis of pregnancy induced hypertensive umbilical arteries. J Evolution Med Dent Sci 2021;10(39):3466-3469, $10.14260 /$ jemds/2021/702

Submission 04-08-2020,

Peer Review 10-08-2021,

Acceptance 16-08-2021, Published 27-09-2021.

Copyright () 2021 JEMDS. This is an open access article distributed under Creative Commons Attribution License [Attribution 4.0 International (CC BY 4.0)] 


\section{BACKGROUND}

The human umbilical arteries form an important component involved in the exchange of materials between the foetus and the mother. Hyrtl's anastomosis, connecting the two umbilical arteries has been described by many authors.1,2 Many theories have been put forward explaining its function in equalizing the pressure between the two arteries. $1,2,3,4,4,6$

The importance of an intact endothelium and recognizing the value of the blood vessel endothelium in the uteroplacental circulation has been greatly increased. Reduction in the uteroplacental blood flow, abnormal placentations are often associated with pregnancy-induced hypertension. ${ }^{7}$

In a specimen of pre-eclampsia, an ultrastructural study was performed and the study revealed extensive endothelial cell injury. A two-staged disease was attributed to it. Firstly, the uteroplacental blood flow is affected and secondly the placental ischemia affecting the maternal and foetal circulation. ${ }^{8}$

Disrupted endothelial cells were reported from the umbilical arteries of infants from pre-eclamptic women. ${ }^{9}$

Ultrastructural study in normal umbilical arteries by Inger Asmussen revealed the endothelial cells in the intimal layer to be closely held together by tight junctions and gap junctions and these cells containing the cell organelles, the rough endoplasmic reticulum, mitochondria and Golgi apparatus. ${ }^{10} \mathrm{~A}$ thin irregular basement membrane of $0.1 \mu$ separated the media from the intimal layer.

Histological study of blood vessels of foetal umbilical cords demonstrated in the umbilical arteries, absence of external elastic lamina, adventitia or vasa vasorum. Internal elastic lamina is not distinguishable. At the junction of the tunica intima and media, a discontinuous segment of elastic lamina was reported. The arrangement of smooth muscle cells was mostly helical or circular displaying a dense intercellular matrix. The smooth muscle cells of the intima were, closely and longitudinally arranged with varying thickness and partial folding into longitudinal pleats and the lumen narrow and distorted. The smooth muscle cells were found to be thin, elongated and wavy as if relaxed or possibly degenerated.

In the ultrastructural study, in the media, the smooth muscles were not closely packed and irregularly in the outline of the nuclei and peripheral concentration. The location of the cell organelles was predominantly perinuclear and para nuclear and in the myofibrils, cytoplasmic densities were seen. Smooth muscle cells were abundant in glycogen and were seen as elongated perinuclear collections of black granules, in the proximity of the plasma membrane. Postpartum autolysis showed loss of cristae in mitochondria and a clear matrix. The thin and deficient basement membrane of the smooth muscle cell was occasionally multiple featuring unusual elevations with delicate folds often separated from the plasma membrane. Deep cytoplasmic extension held the endothelial cells of the umbilical artery with the underlying tunica intima. Nuclei of the endothelial cells exhibited peripherally located chromatin. The basement membranes were separated from the endothelial plasma membrane and it was thick and discontinuous.

Weiss reported in the muscle layer the smooth muscle cell of the umbilical artery was longitudinally oriented with the consistent proliferation of the intima that develops during gestation. In post-natal life, the concept of tunica intima and media (inner and outer muscle layer) was clearly demarcated by the prominent elastic tissue. ${ }^{11}$

Roach in their studies reported the stellar lumens of umbilical arteries and the collapsed vessels were due to the intimal mounds (valves of Hoboken). ${ }^{12}$ Postpartum the contraction of the longitudinal muscles in the media and intima shortens and the girth increases laterally, encroaching the lumen and this explains the narrowing of the lumen.

The endothelial muscular layer of the Hyrtl's anastomosis has however received scant attention. Indeed to the better of our knowledge only one brief description on histology of the structure of the muscular layer of Hyrtl's anastomosis by Ullberg exists. ${ }^{13}$

Therefore, the present study was conducted to study the ultrastructural features of Hyrtl's anastomosis of normotensive and hypertensive umbilical arteries.

\section{METHODS}

20 cases of Hyrtl's anastomosis of pregnancy-induced hypertension and normal were collected and processed for histological examination from the year 2017 - 2018 at Sikkim Manipal Institute of Medical Sciences.

A cross-sectional study was carried out to assess the variable anatomy in the Hyrlt's anastomosis for a better understanding of the physical characteristics involving placentas from normotensive and pregnancy-induced hypertensive mothers.

Samples taken were approved by the Institutional Ethics Committee and the patient's written consent was obtained. Procedures for the histological sections followed. Fixation in $10 \%$ formalin solution, dehydrated in graded ethanol series, cleared in xylene and embedded in paraffin. Sections of $5 \mu \mathrm{m}$ Hyrtl's anastomosis were stained with haematoxylin and eosin (H \& E) and were identified under a microscope $(10 \mathrm{x}$, 20x).

For the ultrastructural study, the specimens were immediately dissected after the delivery. For TEM the portion of the Hyrtl's anastomosis was carefully dissected out and cut into small blocks $(1 \mathrm{~mm})$ and immediately transferred to $3 \%$ cacodylate buffered glutaraldehyde $(\mathrm{pH}$ 7.4) for a minimum of 4 hours. Post fixation was performed in $1 \%$ buffered osmium tetroxide for 1 hour. Tissue rinsed in $0.1 \mathrm{M}$ cacodylate buffer for 10 minutes. Tissue blocks were dehydrated in graded ethanols, cleared in propylene oxide, and embedded in resin (Agar 100). After the tissue blocks were prepared, ultra-thin sections were cut off $40 \mathrm{~nm}$ thickness; sections were taken on 200 mashes thin bar Nickel grid and stained with $2 \%$ Uranyl acetate and $0.2 \%$ lead citrate. Then it was ready to observe in TEM. Images were taken at $100 \mathrm{kV}$. TEM was FEI Tecnai Biotwin 12.

\section{Inclusion Criteria}

Inclusion criteria included women with pregnancy-induced hypertension if their arterial blood pressure with systolic $\geq$ $140 \mathrm{~mm} \mathrm{Hg}$ and diastolic $\geq 90 \mathrm{~mm} \mathrm{Hg}$ measured on two or more occasions at least after the $20^{\text {th }}$ week of gestation with or without oedema. 


\section{Exclusion Criteria}

Due to the inadequate number of cases essential hypertensive cases were excluded.

\section{Statistical Analysis}

Independent t-test was considered in the analysis for continuous variables among two or more groups. $\mathrm{P} \leq 0.05$ was considered significant. SPSS 20.0 was used for data analysis.

\section{RESULTS}

In transmission electron microscopy of pregnancy-induced hypertensive Hyrtl's anastomosis the muscular layer was disrupted when compared to normal Hyrtl's anastomosis. The muscular layer was thickened (Table. 1) and blood clots were also seen with hyalinization in pregnancy-induced hypertensive Hyrtl's anastomosis. (Fig; 1)

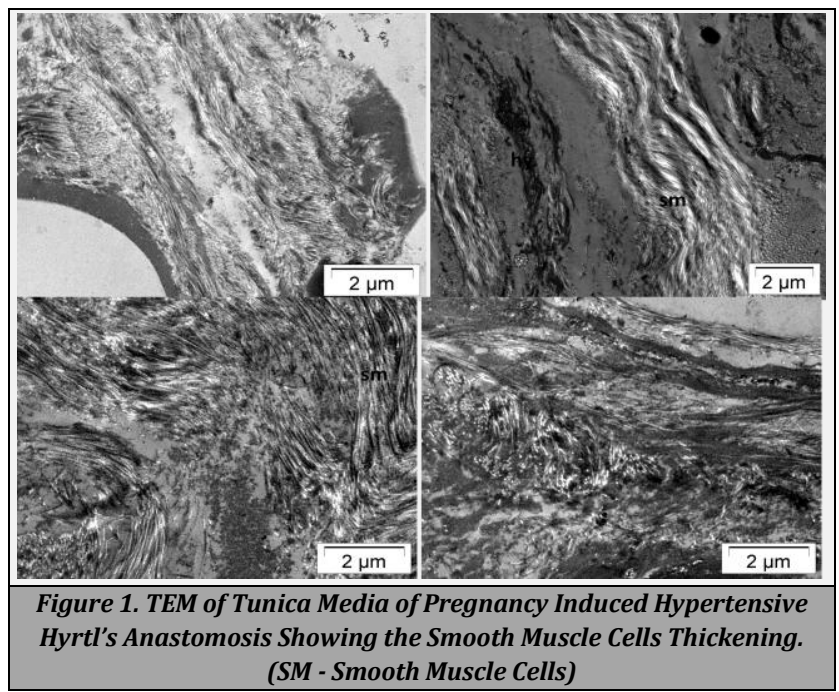

Irregularities in the endothelial lining and the cells of the smooth muscles were flat and thick similar to fibroblast. In the tunica intima of normal Hyrtl's anastomosis, the endothelial cells were placed in close proximity and were joined by gap junctions. The arrangement of the smooth muscles was loose and the muscle cells were long and slender.

(Fig. 2)

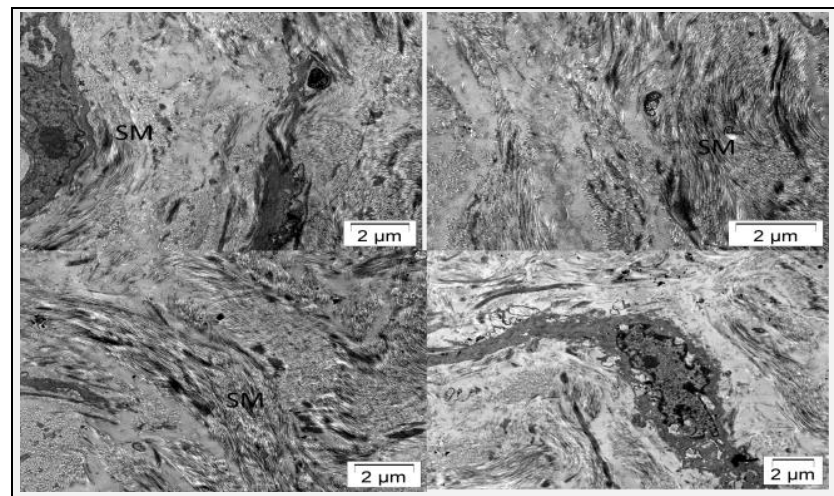

Figure 2. TEM of Tunica Media of Normal Hyrtl's Anastomosis. (SM - Smooth Muscle)

\begin{tabular}{|ccc|}
\hline Specimen & $\begin{array}{c}\text { Thickness of the } \\
\text { Muscle Layer }(\mathbf{m m})\end{array}$ & $\begin{array}{c}\text { Hyalinization } \\
\text { Thickness (mm) }\end{array}$ \\
Normal Hyrtl's & 0.312 & 0.41 \\
Mean & \pm 0.13 & \pm 0.31 \\
St.dev & 30 & 30 \\
N & 0.0231 & 0.0566 \\
S.E & 0.39 & 0.32 \\
PIH Hyrtl's & \pm 0.214 & \pm 0.18 \\
Mean & 30 & 30 \\
St. Dev & 0.0391 & 0.0329 \\
N & -1.7058 & 1.375 \\
S.E & 0.094 & 0.174 \\
T- Value & Palue & \\
\hline Pable 1. Measurement of the Thickness of Muscle Layer in Normal and \\
Pregnancy Induced Hypertension Hyrtl's Anastomosis. \\
\hline
\end{tabular}

\section{DISCUSSION}

A varied difference was observed in the Hyrtl's anastomosis of pregnancy-induced hypertensive umbilical cords when compared to that of normotensive umbilical arteries.

The present findings are in accordance with previous studies in relation to smooth muscle fibres. Studies related to the ultrastructure of human umbilical vessels at term are numerous ${ }^{10,12,14}$ but there are no studies comparing the ultrastructure of the Hyrtl's anastomosis of pregnancy induced hypertension.

Reports on the orientation of the smooth muscle cells were done by many authors, the arrangement of the smooth muscle layer in two distinct layers: an outer circular layer surrounding an internal longitudinal layer. ${ }^{15}$

Hamilton and Boyd reported the arrangement being longitudinal mainly with intermittent circular layers, whereas in term umbilical vessels, a predominant helicoidal layer was proposed by Gebrane - Younes et al.16,17 The present study showed that the circular muscle layer was predominant in the Hyrtl's anastomosis of pregnancy-induced hypertensive and normotensive groups.

In the peripheral region of the vessel wall, fibroblast like cells were seen. Takechi et al. described in detail the fibroblast like cells in the umbilical artery and their cells act as an adventitial layer around all three vessels of the umbilical cord. ${ }^{18}$

In a fully patent umbilical artery, the endothelial lining arrangements were described and composed of spindleshaped cells, which were longitudinally arranged and connected by cell junctions. ${ }^{19}$

Our findings in normal Hyrtl's anastomosis were similar and revealed a relatively smooth and uniform endothelial lining which were connected by tight junctions.

In the preeclamptic groups, the muscular layer was thicker than in normal pregnancies as reported by Junek et. al. ${ }^{20}$ These observations were made in the tunica intima and media. Similar observations were noted from our study.

The muscular layer of Hyrtl's anastomosis of pregnancy induced hypertensive was thicker and the smooth muscle cells appeared to be thicker with short abrupt ends, the cells were also flat whereas in normotensive, the smooth muscle cells were arranged in few layers and loosely with visible space and circular arrangement with the cells being slender in shape.

The absence of nerves, vasa vasorum or elastic lamina were observed throughout the whole investigation of Hyrtl's 
anastomosis which was in agreement with the findings of Manuel et al. who demonstrated in the umbilical arteries. ${ }^{21}$

\section{CONCLUSIONS}

From the study conducted, transmission electron microscopy revealed thickening and hyalinization along with disrupted muscular fibres and blood clots were visible. Overall, the adventitia, vasa vasorum, nerve fibres and the elastic lamina were not seen. In summary, there was a difference in the structure of the vessel wall of the normotensive Hyrtl's anastomosis and pregnancy-induced hypertensive Hyrtl's anastomosis. The effects of hypertension brought about structural changes in the blood vessels which might probably have an effect on the fetoplacental circulation and therefore adversely affecting the foetal outcome.

\section{Limitations of the Study}

The length of the Hyrtl's anastomosis ranging from $1 \mathrm{~mm}$ $5 \mathrm{~mm}$, making the sample collection restricted to few numbers and also the availability of the pregnancy-induced hypertensive samples within a stipulated time, hindered the study.

Data sharing statement provided by the authors is available with the full text of this article at jemds.com.

Financial or other competing interests: None.

Disclosure forms provided by the authors are available with the full text of this article at jemds.com.

\section{REFERENCES}

[1] Hyrtl J. Die Blutgefa“" sse der Menschlichen Nachgeburt in Normalen und Abnormen Verha" Itnissen. Braumu" ller Verlag, Vienna. 1870.

[2] Pri'man J. A note on the anastomosis of the umbilical arteries. Anat Rec 1959;134:1-5.

[3] Benirschke K, Kaufmann P. Pathology of the Human Placenta. New York: Springer - Verlag 1995.

[4] Bacsich P, Smout CF. Some observations on the foetal vessels of the human placenta with an account of the corrosion technique. J Anat 1938;72(Pt 3):358-64.1.

[5] Predanic M, Kolli J, Yousefzadeh P, et al. Disparate blood flow patterns in parallel umbilical arteries. Obstet Gynecol 1998;91(5 Pt 1):757-60.

[6] Raio L, Ghezzi F, Di Naro E, et al. Prenatal assessment of the Hyrtl anastomosis and evaluation of its function. Human Reproduction 1999;14(7):1890-3.
[7] Brosens I, Dixon HG, Robertson WB. Fetal growth retardation and the arteries of the placental bed. British Journal of Obstetrics and Gynaecology 1977;84(9):65663.

[8] Robertson WB, Brosens I, Dixon HG. The pathological response of the vessels of the placental bed to hypertensive pregnancy. Journal of Pathology and Bacteriology 1967;93(2):581-92.

[9] Roberts JM, Taylor RN, Musci TJ, et al. Pre - eclampsia: an endothelial cell disorder. American Journal of Obstetrics and Gynaecology 1989;161(5):1200-4.

[10] Asmussen I. Ultrastructure of human umbilical arteries. Studies on arteries from newborn children delivered by non-smoking white group $\mathrm{D}$, diabetic mothers. Circulation Research 1980;47(4):620-6.

[11] Weiss L, Greep RO. Histology. New York, NY: McGrawHill Publication 1977: p. 976-7.

[12] Roach MR. A biophysical look at the relationship of structure and function in the umbilical artery. In: Comline KS, Cross KW, Dawes GS, et al. eds. Foetal and Neonatal Physiology. Cambridge UK: Cambridge University Press 1973: p. 141-63.

[13] Ullberg U, Sandstedt B, Lingman G. Hyrtl's anastomosis, the only connection between the two umbilical arteries. A study in full term placentas from AGA infants with normal umbilical artery blood flow. Acta Obstet Gynecol Scand 2001;80(1):1-6.

[14] Takagi T, Leszczynski D, Toda T, et al. Ultrastructure of the human umbilical artery and vein. Characterisation and quantification of lipid laden cells. Acta Pathologica Japonica 1985;35(5):1047-55.

[15] Spivack M. The anatomic peculiarities of the human umbilical cord and their clinical significance. Am J Obstet Gynecol 1946;52:387-401.

[16] Boyd JD, Hamilton WJ. The Human Placenta. Cambridge: W Heffer \& Sons Ltd., 1970.

[17] Gebrane-Younes J, Hoang NM, Orcel L. Ultrastructure of human umbilical vessels: a possible role in amniotic fluid formation. Placenta 1986;7(2):173-85.

[18] Takechi K, Kuwabara Y, Mizuno M. Ultrastructure and immunehistochemical studies of Wharton's jelly umbilical cord cells. Placenta 1993;14(2):235-45.

[19] Rockelein G, Scharl A. Scanning electron microscopic investigations of the human umbilical artery intima. A new conception on postnatal arterial closure mechanism. Virchows Archiv A Pathol Anat 1988;413(6):555-61.

[20] Junek T, Baum O, Lauter H, et al. Preeclampsia associated alterations of the elastic fibre system in umbilical cord vessels. Anat Embryol 2000;201(4):291-303.

[21] Blanco MV, Vega HR, Giuliano R, et al. Histomorphometry of umbilical cord blood vessels in pre-eclampsia. The Journal of Clinical Hypertension (Greenwich) 2011;13(1):30-4. 